\title{
Relation between the Behavior of Water and Hydrogen Bonding in Poly(hexamethylene adipamide) Films with Different End Group Balance
}

\author{
Toshinori Kolzumi, Hirobumi Ono, Masahiro TomokiYo, ${ }^{*}$ and Kunihiko OKaJIMA
}

\author{
Fundamental Research Laboratory for Natural \& Synthetic Polymers, \\ Asahi Chemical Industries Co., Ltd., 11-7 Hacchownawate, \\ Takatsuki, Osaka 569, Japan \\ * Fiber R\&D section, Leona Plant, Leona Business Division, \\ Ahasi Chemical Industries Co., Ltd., 4-3623 Nagahama, \\ Nobeoka, Miyazaki 882, Japan
}

(Received January 4, 1996)

\begin{abstract}
As an extension of the previous studies [M. Tomokiyo et al., submitted to Sen-i Gakkaishi], an attempt was made to elucidate the intrinsic role of terminal groups in the hydrogen bonding formation and the existing state of water in poly(hexamethylene adipamide) (nylon 66) with different molar fraction of amino end group $f_{\mathrm{N}}$. $\left(f_{\mathrm{N}}=[\mathrm{NH} 2] /([\mathrm{NH} 2]+\right.$ $[\mathrm{COOH}]))$ For this purpose, the heat-pressed nylon 66 films were subject to infrared (IR) and $\tan \beta-t$ analyses and at the same time the films which absorbed $10 \mathrm{wt} \%$ of water were subject to ${ }^{1} \mathrm{H}$ NMR measurements to determine relaxation time $T_{1}$ of water. Analyses on the change in the wave numbers of $\mathrm{NH}$ and $\mathrm{CO}$ stretching vibrations $\left(\kappa_{v \mathrm{NH}}, \kappa_{v \mathrm{CO}}\right)$, the activation energy evaluated from the temperature dependence of $\kappa_{v \mathrm{NH}}$ and $\kappa_{v \mathrm{CO}}$ and the activation enthalpy and entropy for $\alpha_{\mathrm{a}}$ and $\alpha_{\mathrm{b}}$ relaxations indicated that the stronger hydrogen bond is formed for nylon 66 with larger $f_{\mathrm{N}}$, which corresponds to the higher molecular packing density and higher activation energy for flow of the melt for these polymers. ${ }^{1} \mathrm{H}$ NMR revealed that water which penetrated into nylon 66 is composed of two electro-magnetically different species, one of which might be the ionized water by end groups, and those species are also composed of at least two components with shorter $T_{1}\left(T_{1 . \mathrm{B}}\right)$ and with longer $T_{1}\left(T_{1, \mathrm{~A}}\right)$. The existence of ionized water was supported by the $\mathrm{pH}$ measurement of water containing nylon 66 . The both $T_{1}$ were shorter for nylon 66 with lower $f_{\mathrm{N}}$, denoting that the nylon interacts more strongly with water, which is quite comparative to the facts that nylon 66 with low $f_{N}$ exhibits the lower resistance to the penetration of water for this polymer. These facts leaded to an idea that water in polyamide is ionized by the polar terminal end groups and based on this idea a tentative hydrogen bonding for nylon 66 with high and low $f_{\mathrm{N}}$ (amino end rich and carboxyl end rich, respectively) is proposed.

KEY WORDS Poly(hexamethylene adipamide) / End Group Balance / Amino End Group / Carboxyl End Group / Relaxation / Ionization / Hydrogen Bonding /
\end{abstract}

Authors have already pointed out the importance of the balance of terminal groups of poly(hexamethylene adipamide) (nylon 66) in the water adsorption behavior, the rheological and thermal properties and the crystallization kinetics of the polymers ${ }^{1}$ and the fiber structure formation during its melt-spinning process. ${ }^{2}$ All these data have revealed that 1) nylon 66 with higher molar fraction of amino end group $f_{\mathrm{N}}$ is more resistant to the water adsorption, lowers the crystallization rate but exhibits the lower molecular mobility brought about by an increase in the activation energy for flow of the polymer melt and 2) the nylon 66 with larger $f_{\mathrm{N}}$ is fabricated into the fiber having amorphous region characterized by stronger cohesive nature of molecular chains. All result seems to support the idea that nylon 66 with high $f_{\mathrm{N}}$ has inherently stronger molecular interaction in the amorphous region to hinder the structural change induced by heat and humidity to some extent. However, the essential reason for the above phenomena has not been fully understood yet. Since polyamide has a potential ability to form hydrogen bond between amide groups (amino hydrogen and carboxyl groups) and it has unavoidably some water in any shape, the hydrogen bond might play an important role in any instance and is naturally influenced by the existence of water in polymer. The importance of water on structure changes and some properties for polyamide has been insisted by many authors. ${ }^{3-7}$ Wasias found so-called water-induced crystallization for nylon $6 .^{3}$ By dilatometric technique Kettle noted the glass-transition temperature $T_{\mathrm{g}}$ of nylon 6 as a function of water content decreased first sharply, then slowly with an increase in water content with plateau region (water content region $3-5 \mathrm{wt} \%$ ). ${ }^{4}$ The transition of $\alpha_{2}$ to $\alpha_{1}$ crystal for nylon 66 by water has been reported by Vergelati et al. ${ }^{5}$ and the relaxation times $\left(T_{2}\right)$ of water which penetrated into nylon 66 has been found to be shorter by three order of magnitude than that of bulk water by Fyfe et al. ${ }^{6}$

However, all the literature has ignored the effect of the balance of terminal groups which might facilitate the ionization of water penetrated in polyamide. Thus, in order to explain the phenomenological facts described above the hydrogen bonding in polyamide should be discussed in view of $f_{\mathrm{N}}$ and the existing state of water in the polymer with different $f_{\mathrm{N}}$.

In this paper, we attempt to discuss the above problems in view of the hydrogen bonding and the existing state of water as a function of $f_{\mathrm{N}}$ with aid of infrared (IR) spectroscopy, $\tan \delta-T$ and ${ }^{1} \mathrm{H}$ NMR analyses.

\section{EXPERIMENTAL}

\section{Nylon 66 Films with Different $f_{\mathrm{N}}$}

Three kinds of nylon 66 chips differing in $f_{\mathrm{N}}$ (manufactured by Asahi Chemicals Co., Ltd., Japan) were separately extruded into water bath to form chips again 
using a twin screw-extruder (Laboplasto mill, Toyo Seiki Co., Ltd., Japan) under the following conditions to elase the thermal history imposed on each chip: cylinder temperature, $283^{\circ} \mathrm{C}$; die temperature, $290^{\circ} \mathrm{C}$; screw revolution, $70 \mathrm{rpm}$; feeding rate, $30 \mathrm{rpm}$; extruding volume, $50 \mathrm{~g} \mathrm{~min}^{-1}$

The chips thus obtained were subject to heat-pressing $\left(50 \mathrm{~kg} \mathrm{~cm}^{-2}\right.$ at $290^{\circ} \mathrm{C}$ for $3 \mathrm{~min}$ ) to give films with thickness of $0.08 \mathrm{~mm}$, using a press-forming apparatus (Model AYSR-5, Kanefuji Kinzoku Co., Ltd., Japan). The concentration of terminal groups were determined by the procedure described previously ${ }^{1}$ and the $f_{\mathrm{N}}$ (=number of amino end group/total numbers of amino and carboxyl end groups) were calculated and listed in Table I. The films were conditioned at $20^{\circ} \mathrm{C}$ and $\mathrm{RH}=65 \%$ for 7 days before using in any experiments. The water content of the films was all $1.52( \pm 0.02) \mathrm{wt} \%$ as determined by Carl-Fisher method. (KF-06, VA-06, Mitsubishi Kasei Co., Ltd.).

\section{FT-IR Measurements}

The films were cut into the size with $10 \times 100 \times 0.08 \mathrm{~mm}$ and subject to IR measurements (Model FTS-60A/896, BIO-RAD Co., Ltd., U.S.A.) by ATR method at below glass transition temperature $\left(35-65^{\circ} \mathrm{C}\right)$ with interval of $5^{\circ} \mathrm{C}$ under following operating conditions: crystal plate for ATR, zinc-selen; scanning speed, $80 \mathrm{kHz}$; low pass filter, $30 \mathrm{kHz}$; accumulation, 400 times; resolution, $8.0 \mathrm{~cm}^{-1}$.

The apparent activation energy relating to the strength of hydrogen bond was estimated by the plot of $\ln \kappa_{v \mathrm{NH}}$ and $\ln \kappa_{v \mathrm{CO}} v s .1 / T$. Here, $\kappa_{v \mathrm{NH}}$ and $\kappa_{v \mathrm{CO}}$ are wave number for $\mathrm{NH}$ and $\mathrm{CO}$ stretching vibrations, respectively, and $T$ is the measuring temperature in $\mathrm{K}$.

\section{Tan $\delta-T$ Analysis}

The $\tan \delta-T$ curves for the films with size of $3 \times 40 \times$ $0.08 \mathrm{~mm}$ were recorded on Vibron DDV01FP (Orientec Inc., Japan) under the following conditions: frequency, $1-110 \mathrm{~Hz}$; heating rate, $2^{\circ} \mathrm{C} \mathrm{min}^{-1}$; measuring interval, $1{ }^{\circ} \mathrm{Cmin}^{-1}$; sample length, $20 \mathrm{~mm}$; adding amplitude, $16 \mu \mathrm{m}$; initial charge to film, $115 \mathrm{~g} \mathrm{~mm}^{-2}$; scanning of temperature, $-100-180^{\circ} \mathrm{C}$.

The activation enthalpy $\Delta H^{*}$, entropy $\Delta S^{*}$, and free energy $\Delta F^{*}$ for $\alpha_{\mathrm{a}}$ and $\alpha_{\mathrm{b}}$ relaxations were estimated from the relation between $T_{\max }$ and the corresponding measuring frequency $f_{\max }$ by using Eyring's procedure as follows ${ }^{8,9}$ :

$$
\begin{gathered}
k_{\mathrm{a}} \propto \frac{1}{\tau}=\frac{k T}{h} \exp \left(\frac{-\Delta F^{*}}{R T}\right) \\
=\frac{k T}{h} \exp \left(\frac{-\Delta H^{*}}{R T}\right) \exp \left(\frac{\Delta S^{*}}{R}\right) \\
\omega_{\max } \tau=2 \pi f_{\max } \tau=1 \\
\ln \left(\frac{1}{2 \pi f_{\max }}\right)+\ln \left(\frac{k T_{\max }}{h}\right)=\frac{\Delta H^{*}}{R T_{\max }}-\frac{\Delta S^{*}}{R}
\end{gathered}
$$

where, $k_{\mathrm{a}}$ is Eyring's rate constant; $k$, Boltzmann's constant $\left(1.38066 \times 10^{-23} \mathrm{~J} \mathrm{~K}^{-1}\right) ; h$, the Planck's constant $\left(6.62618 \times 10^{-34} \mathrm{Js}\right) ; R$, the Gas constant $(1.987$ cal $\left.\mathrm{mol}^{-1} \mathrm{~K}^{-1}\right)$; $\tau$, the relaxation time; $\Delta H^{*}$, the activa- tion enthalpy ( $\left.\mathrm{cal} \mathrm{mol}^{-1}\right) ; \Delta S^{*}$, the activation entropy $\left(\mathrm{cal} \mathrm{mol}^{-1} \mathrm{~K}^{-1}\right)$. In addition, activation energy $\Delta E^{*}$ was evaluated by the frequency dependence of $1 / T_{\max }$ as

$$
\Delta E^{*}=-R \frac{\mathrm{d} \ln f}{\mathrm{~d}\left(\frac{1}{T_{\max }}\right)}
$$

\section{$T_{1}$ Measurement of Water in Polymer}

The longitudinal relaxation time $T_{1}$ of the water absorbed in nylon 66 films with highest $f_{\mathrm{N}}$ and lowest $f_{\mathrm{N}}$ was measured by the inversion recovery method on a NMR spectrometer (Model GSX-400, JEOL, Japan) under the following operating conditions: central observation frequency, $399.78 \mathrm{MHz}$; observation width, $128000 \mathrm{kHz}$; data point, $16 \mathrm{k}$; delay time, $4 \mathrm{~s}$; pulse width, $27 \mu$ s for $180^{\circ}$ pulse.

The fundamental Bloch equation ${ }^{10}$ for this relaxation of the magnetization (initial, $M_{0}$; after a time $t, M_{\mathrm{t}}$ ) is given by eq 5 and 6 .

$$
\begin{gathered}
M_{\mathrm{t}}=M_{0}\left[1-2 \exp \left(-\frac{t}{T_{1}}\right)\right] \\
\ln \left[\left(1-\frac{M_{\mathrm{t}}}{M_{0}}\right) / 2\right]=-\frac{t}{T_{1}}
\end{gathered}
$$

If the relaxation is composed of two components differing in $T_{1}\left(T_{1, \mathrm{~A}}, T_{1, \mathrm{~B}}\right)$ and the fraction of the latter is given as $\chi_{\mathrm{B}}$ (that is, $\chi_{\mathrm{A}}=1-\chi_{\mathrm{B}}$ ), then the following equations might hold by assumption of the additivity rule.

$$
\begin{array}{r}
M_{\mathrm{t}, \mathrm{A}}=\left(1-X_{\mathrm{B}}\right) M_{0}\left[1-2 \exp \left(-\frac{t}{T_{1, \mathrm{~A}}}\right)\right] \\
M_{\mathrm{t}, \mathrm{B}}=X_{\mathrm{B}} M_{0}\left[1-2 \exp \left(-\frac{t}{T_{1, \mathrm{~B}}}\right)\right] \\
M_{\mathrm{t}, \text { total }}=M_{\mathrm{t}, \mathrm{A}}+M_{\mathrm{t}, \mathrm{B}} \\
\ln \left[\left(1-\frac{M_{\mathrm{t}, \text { total }}}{M_{0}}\right) / 2\right]=\ln \left[\left(1-X_{\mathrm{B}}\right) \exp \left(-\frac{t}{T_{1, \mathrm{~A}}}\right)\right. \\
\left.-X_{\mathrm{B}} \exp \left(-\frac{t}{T_{1, \mathrm{~B}}}\right)\right]+C
\end{array}
$$

Constant term $C$ is introduced to delete the contribution brought about by inhomogeneity of magnetic field. As a reference, $T_{1}$ 's of the deionized water and the cellulose/water system were also measured.

\section{pH Change of Water Containing Nylon 66 Chips}

Nylon 66 chips described above were stood in deionized water for one day and the separated chips were dried in air and finally vaccum-dried at $50^{\circ} \mathrm{C}$. A thirty $\mathrm{g}$ of each resultant chip was immersed in $100 \mathrm{ml}$ of deionized water at $25^{\circ} \mathrm{C}$ and the $\mathrm{pH}$ of the surrounding water was measured as a function of time by a $\mathrm{pH}$ meter (Model F-21, Horiba Co., Ltd., Japan). The $\mathrm{pH}$ of deionized water containing no polymer was also measured as control. 

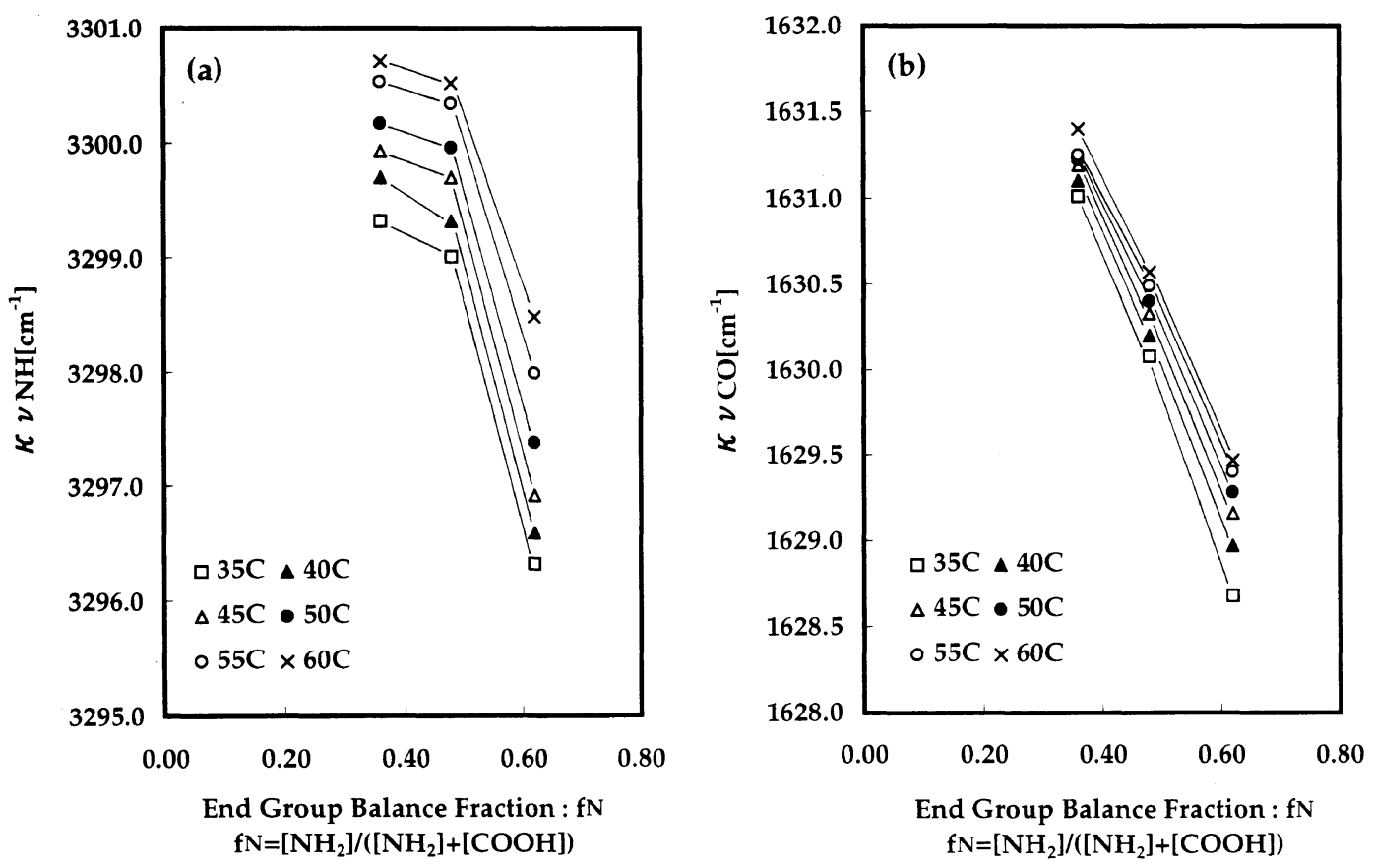

Figure 1. The $f_{\mathrm{N}}$ dependence of wave numbers for $\mathrm{NH}$ and $\mathrm{CO}$ stretching vibrations $\left(\kappa_{v \mathrm{NH}}\right.$ and $\kappa_{v \mathrm{co}}$, respectively) at various measuring temperatures.

\section{RESULTS AND DISCUSSION}

Nature of Hydrogen Bonding of Nylon 66 Films by IR and tan $\delta-T$ Analysis

Figure 1 shows the $f_{\mathrm{N}}$ dependence of the wave numbers for $\mathrm{NH}$ and $\mathrm{CO}$ stretching ( $\kappa_{v \mathrm{NH}}$ and $\kappa_{v \mathrm{CO}}$, respectively) at given temperatures.

Both $\kappa_{v \mathrm{NH}}$ and $\kappa_{v \mathrm{CO}}$ are decreasing functions of $f_{\mathrm{N}}$, indicating that nylon 66 with larger $f_{\mathrm{N}}$ forms stronger hydrogen bond in polymer. Especially, $\kappa_{v \mathrm{NH}}$ drastically shifted towards shorter wave number side when $f_{\mathrm{N}}$ goes from 0.48 to 0.62 . Note that if water in polymer is ionized by end groups, the $f_{\mathrm{N}}$ value of 0.48 is just the turning point from acid to alkali. The ionization of water contacted with nylon 66 chips with different $f_{\mathrm{N}}$ are shown in Figure 2, clearly indicating that the water contacting with carboxyl end rich nylon 66 becomes promptly acidic and the water contacting with amino end rich nylon 66 keeps neutral, offsetting the acidity of water probably by dissolution of carbon dioxide in air. Therefore, the penetrated water is also anticipated to be ionized by the balance of terminal end groups.

In Figure $3 \ln \kappa_{v \mathrm{NH}}$ and $\ln \kappa_{v \mathrm{CO}}$ are plotted against $1 / T$. The activation energies $(\Delta E)$ estimated from Figure 3 for $v_{\mathrm{NH}}$ and $v_{\mathrm{CO}}$ are also higher for the sample with larger $f_{\mathrm{N}}$, although the absolute value for $v_{\mathrm{NH}}$ is larger than that for $v_{\mathrm{CO}}$, as shown in Figure 4. Far lower $\Delta E$ values evaluated here than that reported for hydrogen bond (3- $8 \mathrm{kcal} \mathrm{mol}^{-1}$ ) might be explained by the fact that the present experiment was carried out below $T_{\mathrm{g}}$. This in turn means that we just evaluate the vibrational movement of the hydrogen bonding in a kind of molecularly frozen state. Then, if the hydrogen bond is formed by purely $\mathrm{NH}$ and $\mathrm{CO}$ from polymer alone, one can expect the same $\Delta E$ value, irrespective of estimating procedure. The different results from the analysis on $v_{\mathrm{NH}}$ and $v_{\mathrm{CO}}$ might be influenced by the existing state of water in polymer as pointed out above.

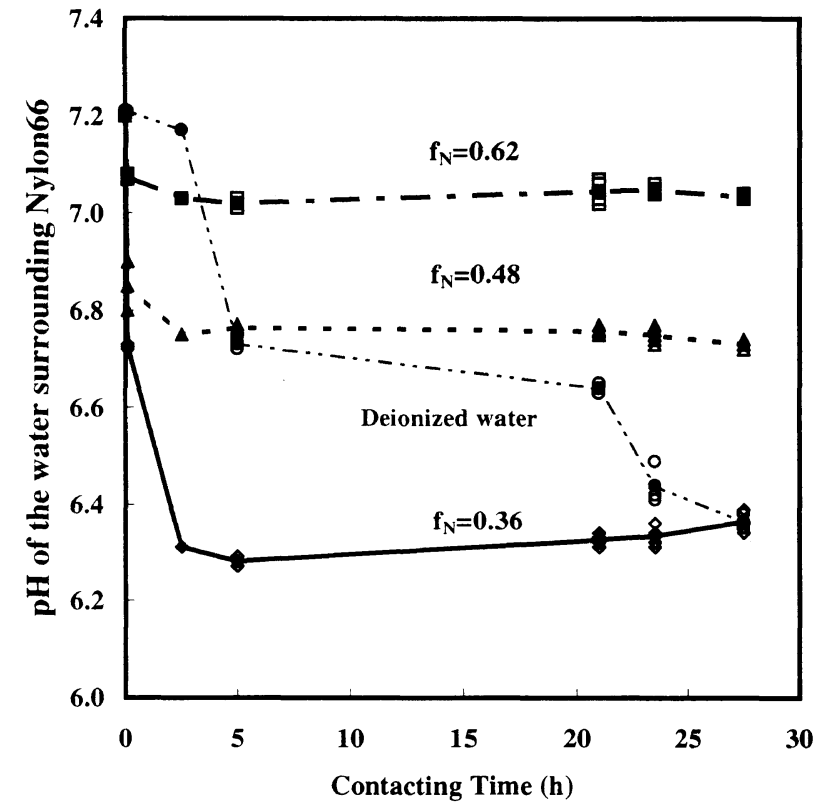

Figure 2. The change in $\mathrm{pH}$ of the water surrounding nylon 66 chips as a function of contacting time: $\bigcirc$, deionized water; $\bigcirc$, nylon 66 with $f_{\mathrm{N}}=0.36 ; \triangle, f_{\mathrm{N}}=0.48 ; \square, f_{\mathrm{N}}=0.62$.

Figure 5 shows the $\tan \delta-T$ curves for nylon 66 films. Two $\alpha$ (referred as to $\alpha_{\mathrm{a}}$ and $\alpha_{\mathrm{b}}$ for convenience) and $\beta$ dispersions are seen around $80^{\circ} \mathrm{C}, 30^{\circ} \mathrm{C}$, and $-70^{\circ} \mathrm{C}$, respectively. $\alpha$ dispersion has been known to shift toward around $c a .0^{\circ} \mathrm{C}$ with an increase in water content in nylon 66 and is attributed to micro Brawnian motion of segment related to hydrogen bonding. ${ }^{11}$ Prevorsek $^{12}$ found two $\alpha$ dispersion peaks in the mechanical relaxation measurements on nylon 6 with water content of more than $2.0 \mathrm{wt} \%$, concluded that higher dispersion (corresponding to $\alpha_{\mathrm{a}}$ in the present case) comes from nylon 6 with no water and the lower temperature dispersion (corresponding to $\alpha_{\mathrm{b}}$ in the present case) is from nylon 6 with some water. $\beta$ dispersion has been attributed to 


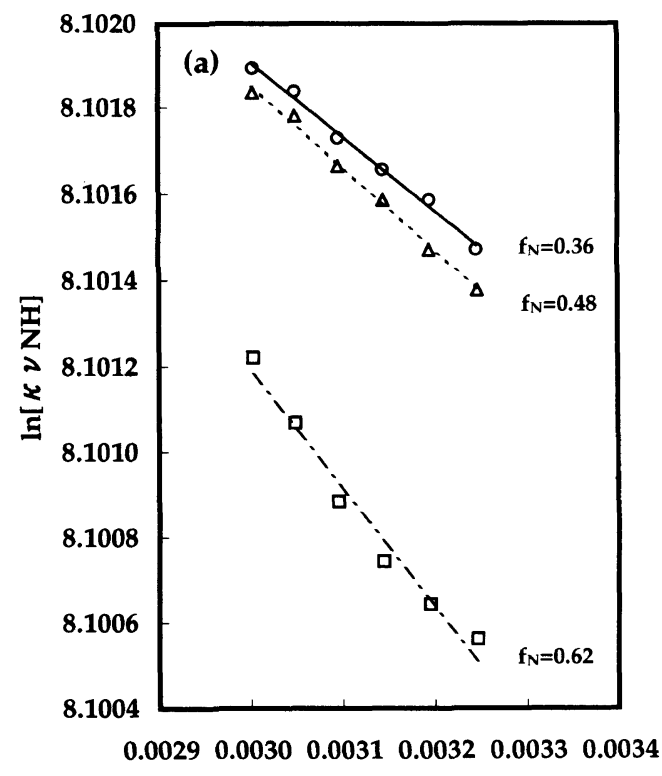

$\mathbf{1} / \mathbf{T}(\mathbf{K})$

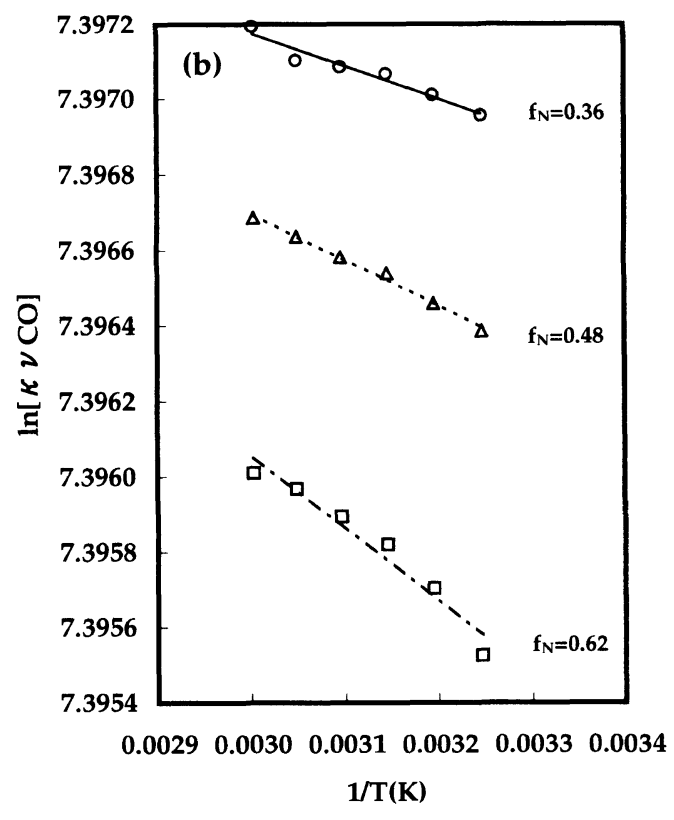

Figure 3. Arrhenius plot of $\mathrm{NH}$ and $\mathrm{CO}$ stretching vibrations ( $\kappa_{v \mathrm{NH}}$ and $\kappa_{v \mathrm{co}}$, respectively): $\bigcirc$, nylon 66 with $f_{\mathrm{N}}=0.36 ; \triangle, f_{\mathrm{N}}=0.48 ; \square, f_{\mathrm{N}}=0.62$.

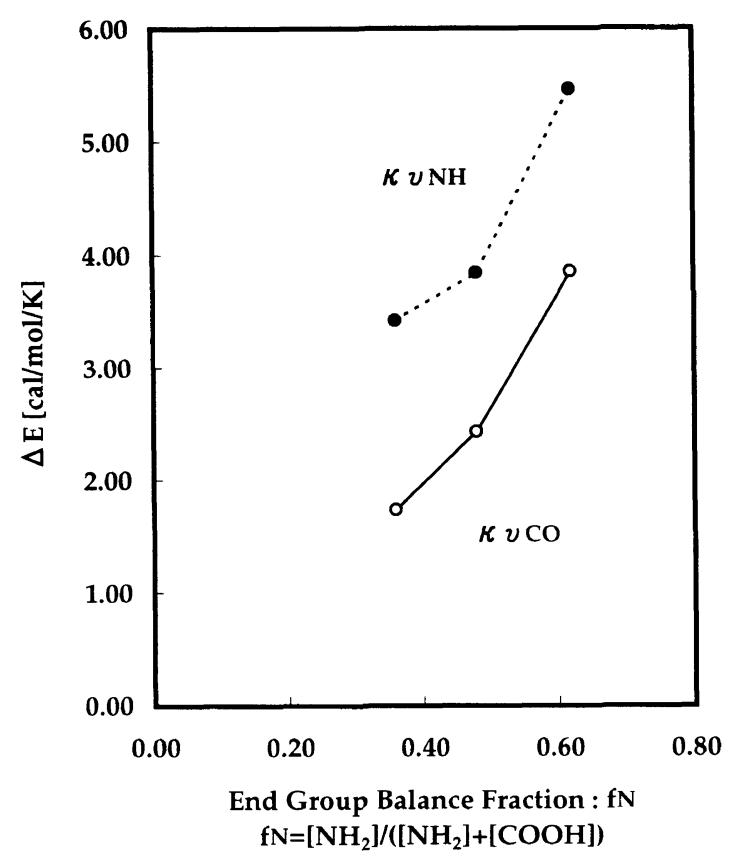

Figure 4. The $f_{\mathrm{N}}$ dependence of activation energy for $\mathrm{NH}$ and $\mathrm{CO}$ stretching vibrations $\left(\kappa_{v \mathrm{NH}}\right.$ and $\kappa_{v \mathrm{CO}}$, respectively): $\bigcirc, \kappa_{v \mathrm{CO}} ; 0, \kappa_{v \mathrm{NH}}$.

segmental motion of the water bonded amide group and the peak temperature has been known to shift towards higher side with a decrease in water content, finally disappearing upon complete drying of nylons. ${ }^{12-15} \alpha_{b}$ becomes more distinct for nylon 66 with lower $f_{\mathrm{N}}$. If we take the assignment for $\alpha_{b}$ described above, the present observation is well correlated with the fact that nylon 66 with lower $f_{\mathrm{N}}$ relatively easily absorbs water. ${ }^{1}$ In turn, the amorphous region characterized by $\alpha_{b}$ dispersion is hard to be formed for nylon 66 with larger $f_{\mathrm{N}}$.

Thermo-kinetic results are summarized in Table I. For both $\alpha_{\mathrm{a}}, \alpha_{\mathrm{b}}$ relaxations $\Delta S^{*} v s . \Delta H^{*}$ plot gives each master line, irrespective of $f_{\mathrm{N}}$, as shown in Figure 6. The linearity of both dispersions is expressed as follows:

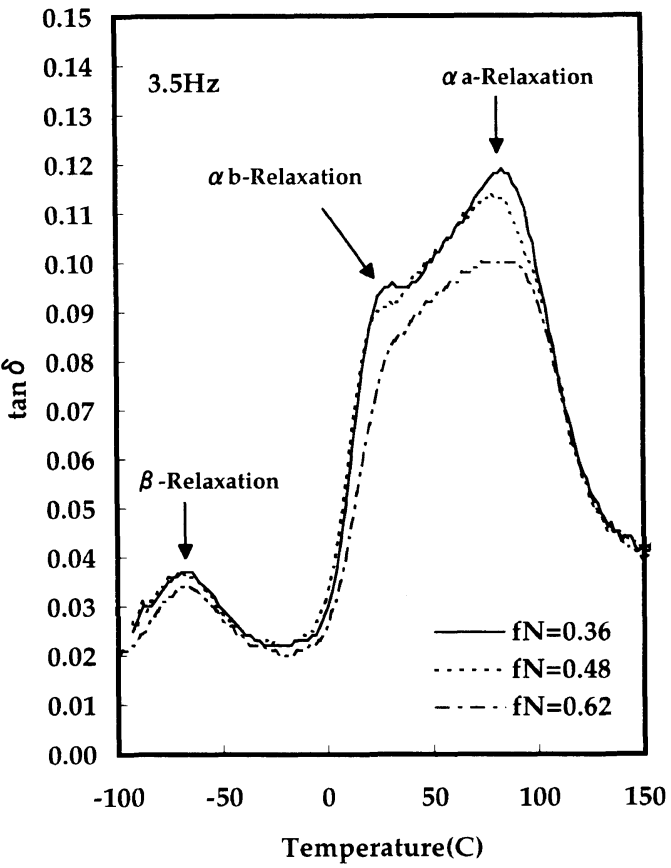

Figure 5. The $\tan \delta-T$ curves for nylon 66 with different $f_{\mathrm{N}}$ : Real line, nylon 66 with $f_{\mathrm{N}}=0.36$; dotted line, $f_{\mathrm{N}}=0.48$; chained line, $f_{\mathrm{N}}=0.62$.

$$
\begin{array}{ll}
\Delta S^{*}=2.66 \times 10^{-3} \Delta H^{*}-36.6 & \text { for } \alpha_{a} \\
\Delta S^{*}=3.16 \times 10^{-3} \Delta H^{*}-32.3 & \text { for } \alpha_{b}
\end{array}
$$

This means that the two dispersions have obviously different relaxation mechanism, but relaxation mechanism for each one of dispersion is inherently the same, irrespective of $f_{\mathrm{N}} . \Delta H^{*}$ and $\Delta S^{*}$ for $\alpha_{\mathrm{a}}$ and $\alpha_{\mathrm{b}}$ relaxations are plotted as a function of $f_{\mathrm{N}}$ in Figure 7. Both $\Delta H^{*}$ and $\Delta S^{*}$ for $\alpha_{\mathrm{a}}$ and $\alpha_{\mathrm{b}}$ relaxations increase with an increase in $f_{\mathrm{N}} . \Delta H^{*}$ for $\alpha_{\mathrm{a}}$ is higher than that of $\alpha_{\mathrm{b}}$ but the reverse is observed for $\Delta S^{*}$. Generally, the movement or rearrangement of the moving unit takes place at molecular level when $\alpha$ relaxation proceeds in polymer system and the order of molecular displacement changes 
at the instance when the moving unit moves by acquiring $\Delta H^{*}$ and overcoming some potential barrier. $\Delta S^{*}$ is a measure for the above order of displacement. Then, the larger $\Delta H^{*}$ for $\alpha_{\mathrm{a}}$ than that for $\alpha_{\mathrm{b}}$ can be understood by

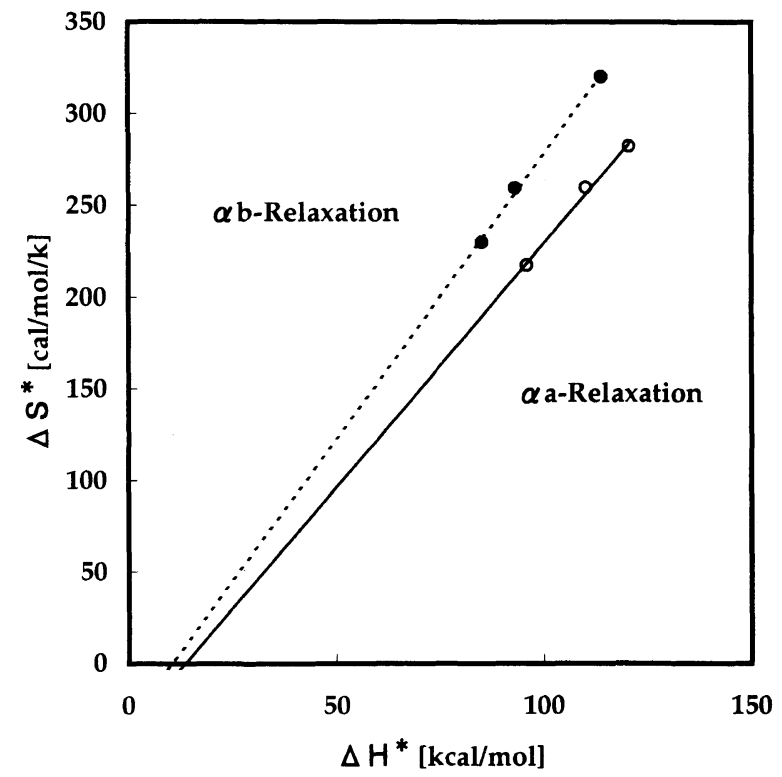

Figure 6. The relation between activation entropy $\Delta S^{*}$ and activation enthalpy $\Delta H^{*}$ for $\alpha_{\mathrm{a}}$ and $\alpha_{\mathrm{b}}$ relaxations of nylon 66 samples with various $f_{\mathrm{N}}: \bigcirc$ (real line), $\alpha_{\mathrm{a}}$ relaxation; (doted line), $\alpha_{\mathrm{b}}$ relaxation. taking the strength of hydrogen bond in both regions into consideration. That is, the molecular packing density in the amorphous region characterized by $\alpha_{\mathrm{a}}$ dispersion is higher due to relatively strong hydrogen bonding than that characterized by $\alpha_{b}$ dispersion.

On the other hand, the reverse tendency for $\Delta S^{*}$ might be explained by an idea that molecular region giving $\alpha_{\mathrm{b}}$ relaxation is considerably influenced by water and the existence of water makes the molecular displacement more orderly. This tendency proved to be much more stronger for nylon 66 with higher $f_{\mathrm{N}}$.

In the case of molecular motion in polymeric solid, a modified theory of self-diffusion of chain led to the following $\Delta S^{*}-\Delta H^{*}$ linear relationship. ${ }^{16}$

$$
\Delta H^{*}=\frac{1}{9 \Delta \alpha} \Delta S^{*}+\Delta H_{\mathrm{tor}}^{*}
$$

where $\alpha$ is the isobaric coefficient of thermal expansion; $\Delta \alpha$ represents the difference in $\alpha$ between the rubbery and glassy states for the $\alpha$ relaxation and $\Delta H_{\text {tor }}^{*}$ corresponds to the internal torsional energy of a polymer chain.

Some authors have related this linear relationship to the thermal expansion coefficient on the basis of the above theory ${ }^{17,18}$. According to the theory, the isobaric coefficient of thermal expansion $\Delta \alpha$ for $\alpha_{a}$ and $\alpha_{b}$

Table I. Thermokinetic parameter for $\alpha$-relaxation

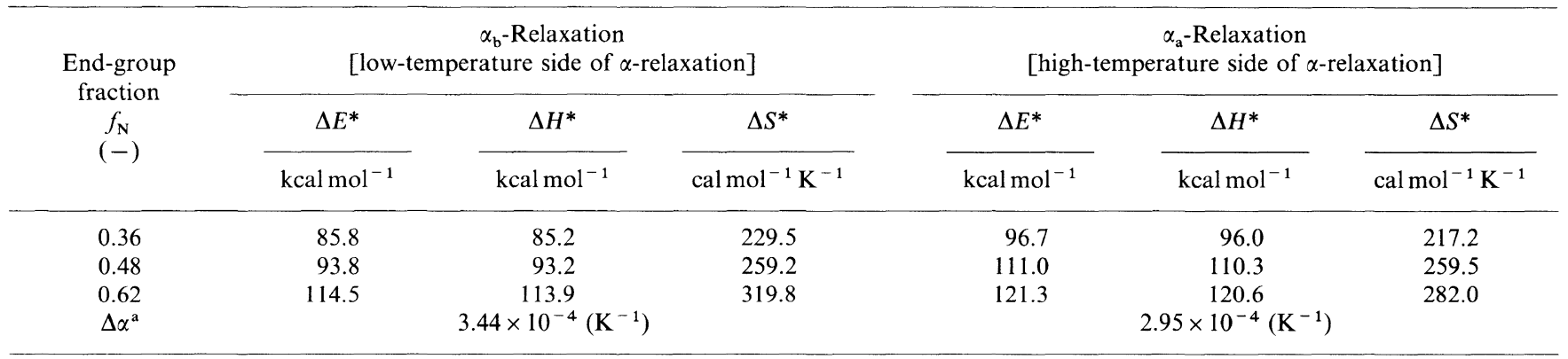

${ }^{\text {a }}$ Evaluated from eq 12.
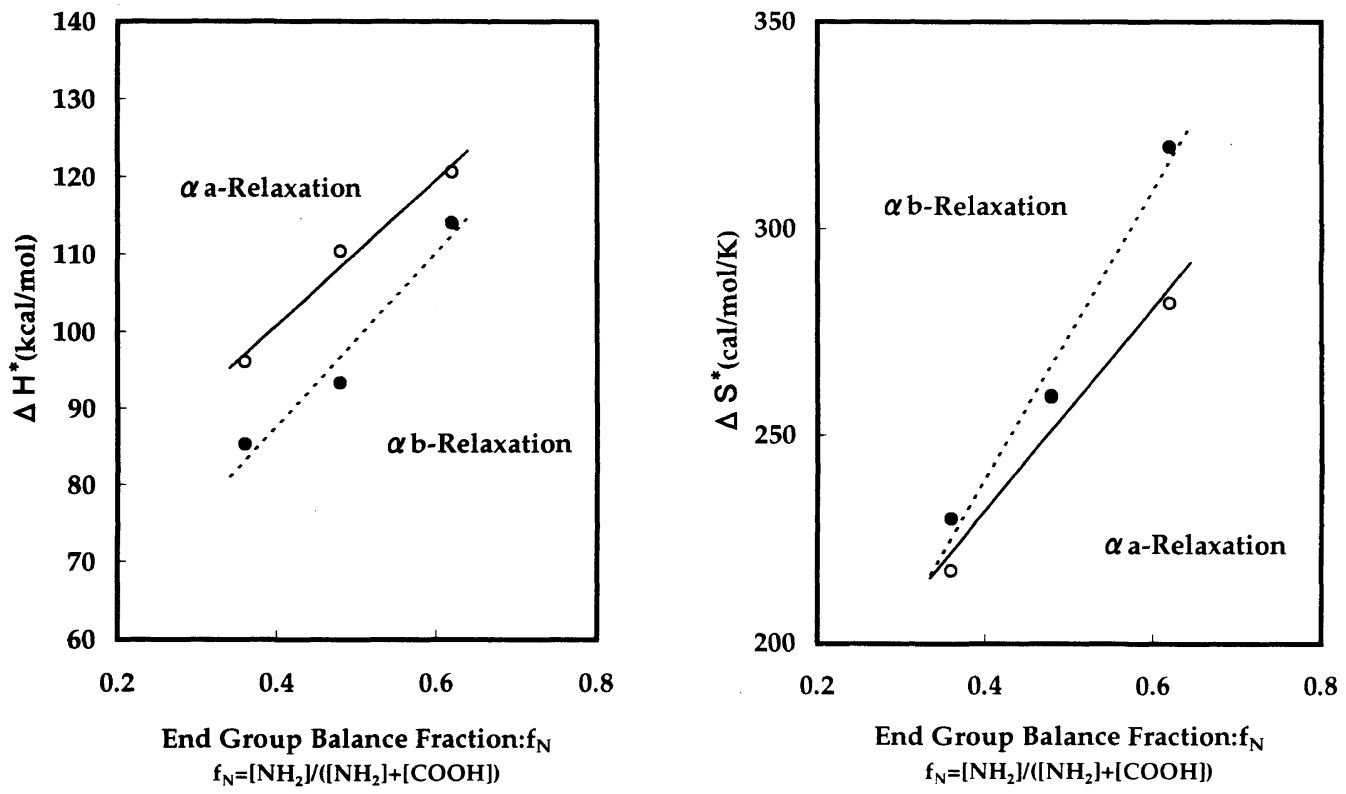

Figure 7. The $f_{\mathrm{N}}$ dependence of the activation enthalpy $\Delta H^{*}$ (a) and activation entropy $\Delta S^{*}$ (b): Symbols are the same as in Figure 6. 
relaxations were evaluated from Figure 6 , to be $2.95 \times 10^{-4}\left(\mathrm{~K}^{-1}\right)$ and $3.44 \times 10^{-4}\left(\mathrm{~K}^{-1}\right)$, respectively. Thermal parameters are collected in Table I. Since $\Delta \alpha$ is the difference between rubbery and glassy states, the above results again confirms that the molecular packing density in the amorphous region related to $\alpha_{\mathrm{a}}$ dispersion is relatively higher than that for $\alpha_{b}$.

\section{The Existing State of Water in Nylon 66}

Figure 8 shows ${ }^{1} \mathrm{H}$ NMR spectra measured at $60^{\circ} \mathrm{C}$ for water absorbed in nylon 66 films with $f_{\mathrm{N}}=0.32$ and 0.62 , and as references the spectra of cellulose/water system are also shown. Obviously, the cellulose/water gives a broad singlet. In contrast to this, nylon 66/water systems exhibit characteristically two separate peaks. This means that the water in nylon 66 is composed of two electro-magnetically different components and this does not means that the water has two components differing in relaxation time, because we can estimate two components with two different relaxation time for a singlet peak for cellulose/water system.

The existence of the ionized water in the vicinity of end groups of polymer might be only possible explanation for the existence of two electro-magnetically different components, attributing a larger peak to ionized one, as proved in Figure 2.

Figure 9 shows the plot of $\ln \left(\left(1-M_{\mathrm{t}} / M_{0}\right) / 2\right) v s . t$ of nylon 66/water systems, including cellulose/water system.

(a) Cellulose

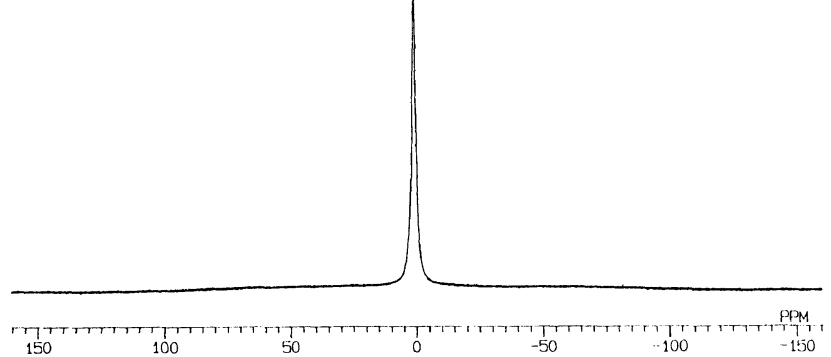

(b) Nylon $66\left(f_{N}=0.36\right)$
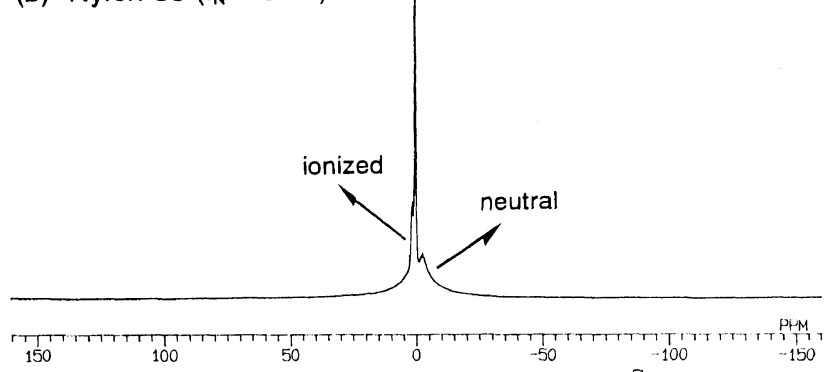

(c) Nylon $66\left(f_{N}=0.62\right)$

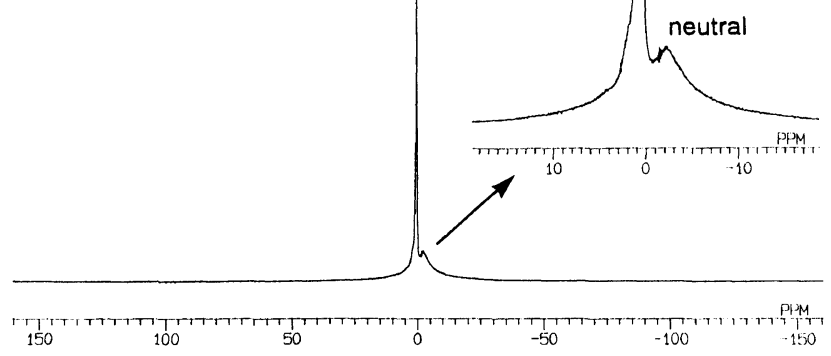

Figure 8. ${ }^{1} \mathrm{H}$ NMR spectra of cellulose (a), nylon 66 with $f_{\mathrm{N}}=0.36$ (b), and nylon 66 with $f_{\mathrm{N}}=0.62$ (c).
The completely linear plot is realized for water but for others considerable deviation from the linearity is found at shorter $t$ region. Note that for nylon 66 systems the total peaks observed in Figure 8 were used in this analysis. Parameter fitting procedure according to eq 8 was made for polymer/water systems and the result is collected in Table II. Two components with different $T_{1}\left(T_{1, \mathrm{~A}}\right.$ and $\left.T_{1, \mathrm{~B}}\right)$ were proved to exist and both values are smaller for nylon 66 with low $f_{\mathrm{N}}$, indicating that water generally more strongly interacts with nylon with low $f_{\mathrm{N}}$ and the fraction of the strongly interacting water is also larger for this polymer. This confirms the previous results obtained in water-absorption experiments. ${ }^{1} T_{1, \mathrm{~B}}$ of nylon $66 /$ water systems is one-order longer than cellulose/ water system. One of possibilities for this difference is that even the strongly interacted water in nylon 66 might be
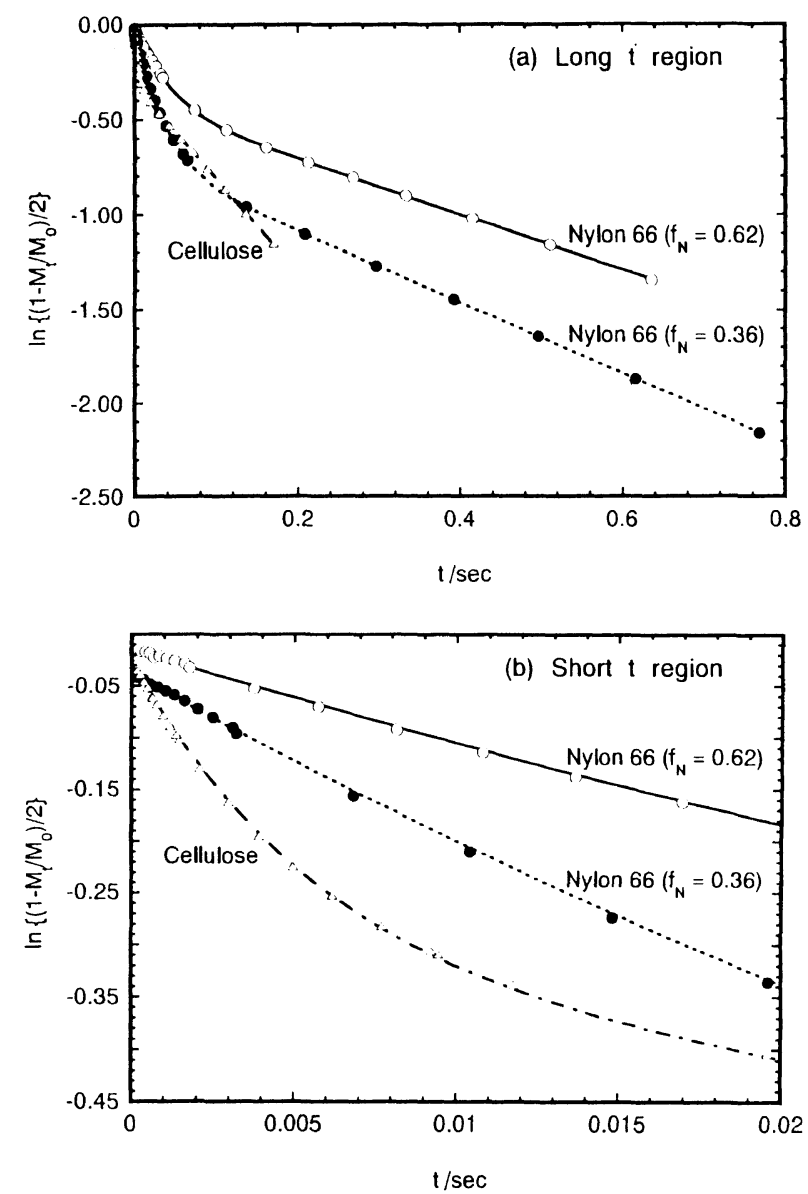

Figure 9. The plot of $\ln \left(\left(1-M_{\mathrm{t}} / M_{0}\right) / 2\right)$ vs. $t$ of nylon $66 /$ water and cellulose/water system: Long $t$ region (a); short $t$ region (b).

Table II. Longitudinal relaxation time $T_{1}{ }^{\mathrm{a}}$ of proton in water and water absorbed in cellulose and nylon 66 with different $f_{\mathrm{N}}$

\begin{tabular}{lccccc}
\hline \multicolumn{1}{c}{ Sample } & $\begin{array}{c}\text { Water } \\
\text { content } / \%\end{array}$ & $T_{1} / \mathrm{s}$ & $T_{1, \mathrm{~A}}{ }^{\mathrm{b}} / \mathrm{s}$ & $T_{1, \mathrm{~B}}{ }^{\mathrm{b}} / \mathrm{s}$ & $\chi_{\mathrm{B}}{ }^{\mathrm{b}, \mathrm{c}}$ \\
\hline Distilled water & 100 & 2.85 & - & - & - \\
Cellulose $^{\mathrm{d}}$ & 12.0 & - & 0.201 & $4.90 \times 10^{-3}$ & 0.250 \\
${\text { Nylon 66 }\left(f_{\mathrm{N}}=0.36\right)}^{\text {Nylon 66 }\left(f_{\mathrm{N}}=0.62\right)}$ & 14.0 & - & 0.534 & $29.9 \times 10^{-3}$ & 0.492 \\
& 14.0 & - & 0.692 & $38.3 \times 10^{-3}$ & 0.336
\end{tabular}

a Observed at $60^{\circ} \mathrm{C}$ using GSX-400 NMR spectrometer. ${ }^{\mathrm{b}}$ Using "two component model" described in the exterimental term. ${ }^{\mathrm{c}} \mathrm{A}$ fraction of water having $T_{1, \mathrm{~B}} \cdot{ }^{\mathrm{d}}$ Membrane sample regenerated in $15 \mathrm{wt} \% \mathrm{H}_{2} \mathrm{SO}_{4}$ solution using cupra ammonium dope at $25^{\circ} \mathrm{C}$. 

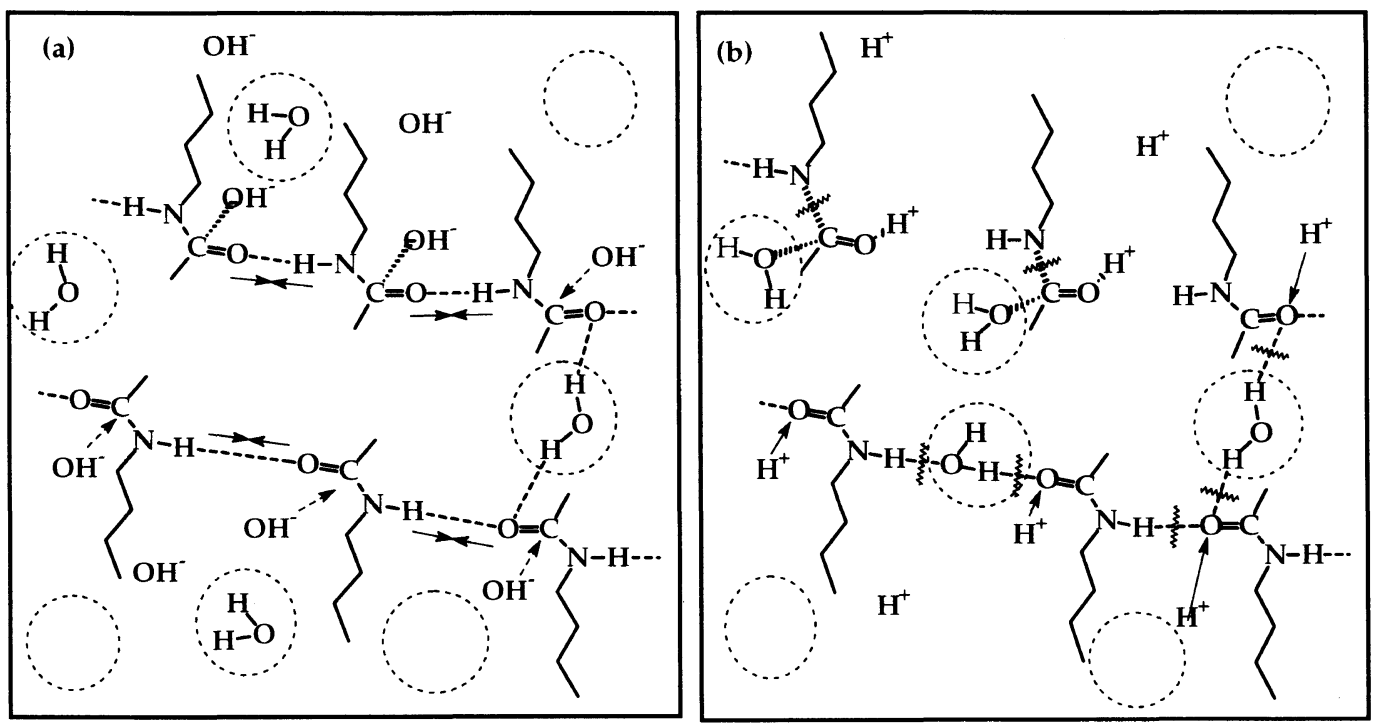

Figure 10. Tentative representation of hydrogen bonding of nylon 66 with $f_{\mathrm{N}}=0.62$ (a) and nylon 66 with $f_{\mathrm{N}}=0.36$ (b).

influenced by the existence of ionize water in polymers, as discussed before. The ionized water may relatively weaken the hydrogen bonding, compared with nonionized water, if water is really incorporated in the hydrogen bonding formation in polar polymers. This tentative explanation can also give a reason for the fact that $\alpha_{\mathrm{a}}$ relaxations for nylon 66, which are said to represent the molecular region dominated by hydrogen bonding, is observed at $80-130^{\circ} \mathrm{C} .{ }^{1}$ As is pointed out above, $\alpha_{\mathrm{b}}$ relaxation is much influenced by water, now we can regard this water to be the water with $T_{1, \mathrm{~b}}$. The reason why the nylon with high $f_{\mathrm{N}}$ (rich in amino end group) is resistant to water and has stronger cohesive nature (for example, resistant to melt flow) and hydrogen bonding could be tentatively explained as shown in Figure 10.

Here, the hydroxyl ions generated for nylon 66 with high $f_{\mathrm{N}}$ may strengthen the original hydrogen bond between polymer by attacking amide carbon (or nitrogen), giving relatively stiff molecular chain assembly (strong cohesive nature ). In contrast to this, the proton originated from nylon 66 with low $f_{\mathrm{N}}$ only works for destruction of the original hydrogen bond, loosening the molecular chain to make room accommodating other waters, and the higher molecular mobility for this polymer might result in higher isothermal crystallization as proved in the previous study. ${ }^{1}$

\section{CONCLUSIONS}

Hydrogen bonding formation of nylon 66 films with different molar fraction of amino end group $f_{\mathrm{N}}$ in relation to the existing state of water penetrated in the polymers. Infrared (IR) and $\tan \delta-T$ analyses revealed that the stronger hydrogen bonding is formed for nylon 66 with higher $f_{\mathrm{N}}$. The penetrated water was proved to be ionized by the balance of end functional groups (carboxyl and animo end groups) of polymer. $T_{1}$ measurement on the water in polymers suggested that water exists as at least two components with shorter $T_{1}\left(T_{1, \mathrm{~B}}\right)$ and larger $T_{1}\left(T_{1, \mathrm{~A}}\right)$, both of which are longer for nylon 66 with higher $f_{\mathrm{N}}$, denoting that the nylon interacts more weakly with water. Based on this idea a tentative hydrogen bonding for nylon 66 with high and low $f_{\mathrm{N}}$ (amino end rich and carboxyl end rich, respectively) is proposed.

\section{REFERENCES}

1. M. Tomokiyo, H. Yamazaki, F. Ise, T. Koizumi, M. Ohtsuka, and K. Okajima, submitted to Sen-i Gakkaishi.

2. M. Tomokiyo, Y. Furue, H. Yamazaki, M. Ohtsuka, and K. Okajima, submitted to Sen-i Gakkaishi.

3. . Wasias, Polymer, 12, 415 (1967)

4. G. J. Kettle, Polymer, 18, 743 (1977)

5. C. Vergelati, A. Imberty, and S. Perez, Macromolecules, 26, 4420 (1993)

6. C. A. Fyfe, L. H. Randall, and N. E. Burlinson, J. Polym. Sci., A, Polym. Chem., 31, 159 (1993).

7. H. W. Starkweather, "Water in Polymer," American Chemical Society, Ed., Washington, D.C., 1980, p 433

8. H. Eyring, J. Chem. Phys., 3, 107 (1935).

9. S. Glasstone, K. J. Leider, and H. Eyring, "The Theory of Rate Processes," McGraw Hill, New York, N.Y., 1941.

10. F. Block, Phys. Rev., 70, 460, (1946).

11. Y. S. Papir, S. Kapur, E. E. Rogers, and E. Baer, J. Polym. Sci., $A-2,10,1305$ (1972).

12. D. C. Prevosek, R. H. Butler, and H. K. Reimshuessel, J. Polym. Sci., A-2, 9, 867 (1971).

13. A. J. Curtis, J. Res. Natl. Bur., 65A, 185 (1961).

14. K. H. Iller and H. Breuer, J. Colloid. Sci., 18, 1 (1963).

15. J. Kolarik and J. Janacek, J. Polym. Sci., C, 16, 441 (1967).

16. S. Isoda and K. Asai, Jpn. J. Appl. Phys., 13, 1333 (1974).

17. M. Zielinski, T. Swiderski, and M. Kryszewski, Polymer, 19, 883 (1978).

18. M. G. McCrum, M. Pizzoli, C. K. Chai, I. Treurnicht, and J. M. Hutchinson, Polymer, 23, 473 (1982). 